\section{ADAPT Software}

Complementing the acquisition system is the ATRIS Data Analysis and Processing Tool (ADAPT) software package. ADAPT makes it easy to examine and analyze the massive amounts of data collected on a typical ATRIS mission. ADAPT is based on open-source LINUX software and enables interactive geographic browsing, scaling, and extraction of specific images for further quantitative analysis. With the integrated Hypack navigational software component, vessel tracks can be plotted, allowing for spatial navigation of the images. Clicking on a point along a track loads the corresponding ATRIS image.

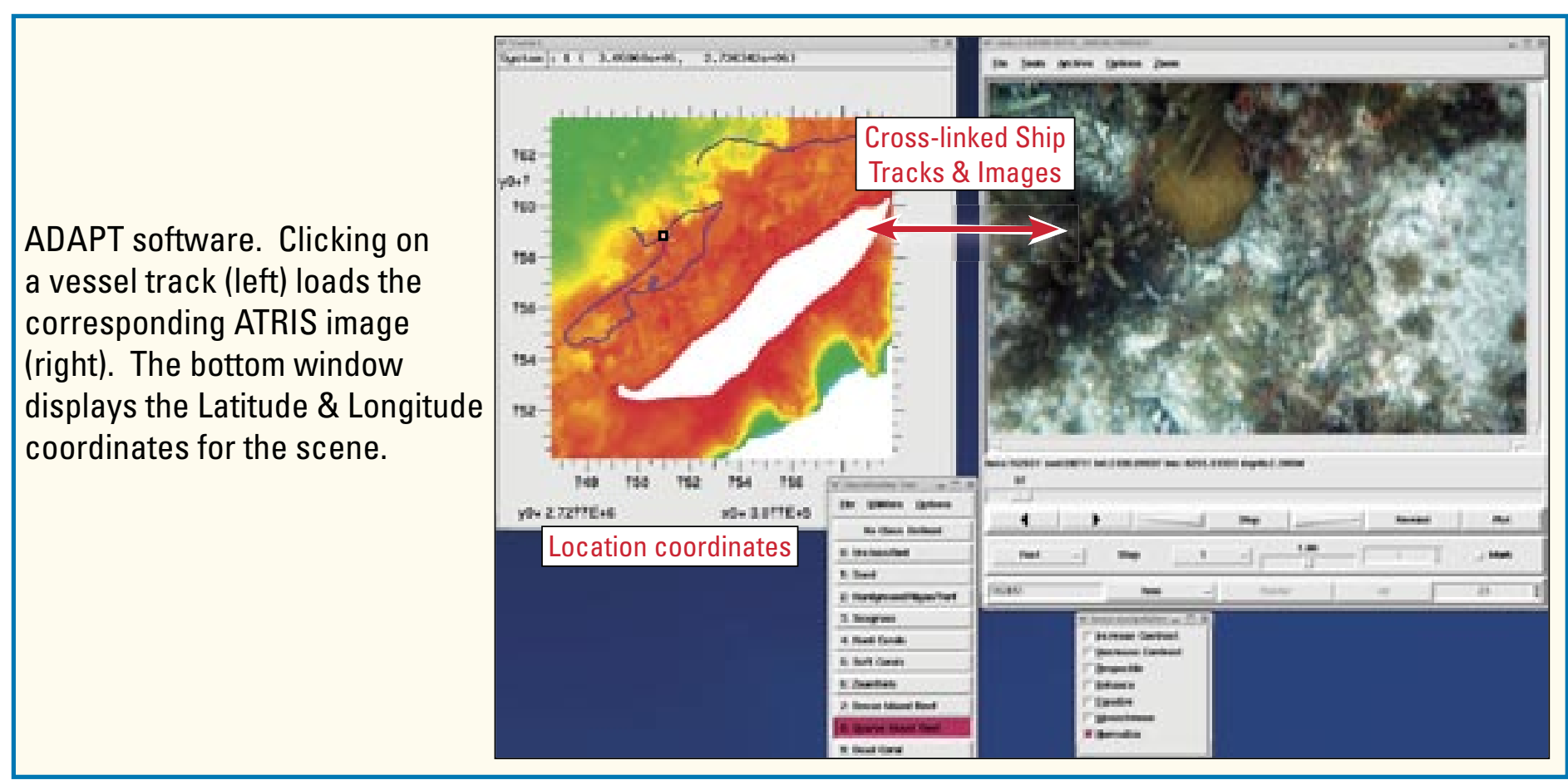

\section{Specifications}

- Camera: 12.4 Megapixel

- Depth sounder accuracy: $\sim 1 \mathrm{~cm}$

- Operating depth range: $3-10 \mathrm{~m}$

- Power: $2 \mathrm{~kW} \mathrm{AC}$ provided by portable generator.

- Boat: $25^{\prime}$ with dry cuddy cabin. Room to mount ATRIS on transom.

For more information contact:

$$
\begin{aligned}
& \text { Dr. John Brock } \\
& \text { jbrock@usgs.gov } \\
& \text { Dr. Dave Zawada } \\
& \text { dzawada@usgs.gov }
\end{aligned}
$$

- Geo-location accuracy: $>\sim 50 \mathrm{~cm}$

\section{Collaboration Opportunities}

Work with us! The USGS actively seeks partnerships to foster further development and application of the ATRIS. Projects involving benthic habitat mapping and/or monitoring will benefit from the geo-located imagery collected with ATRIS. Join the growing ATRIS community!
Center for Coastal and Watershed Studies U.S. Geological Survey

600 Fourth Street South

St. Petersburg, FL 33701 (727) 803-8747

\title{
Along-Track Reef Imaging System (ATRIS)
}

The U.S. Geological Survey has developed the Along-Track Reef Imaging System (ATRIS), a boat-based sensor package for rapidly mapping shallow water $(<10 \mathrm{~m})$ benthic environments. ATRIS acquires high resolution, color digital images that are accurately geo-located in real-time. For a typical mission, 1,000 ATRIS images are captured per hour at a survey speed of 1 knot.

\section{Features}

- Geo-located, scaled digital images - Easily deployed from small boats

- Frame-of-reference video providing an oblique view

- Interactive, geographic browsing of boat position and acquired images

\section{Ongoing Development}

- Unsupervised classification algorithms

- Topographic complexity estimation

- Database with web-interface

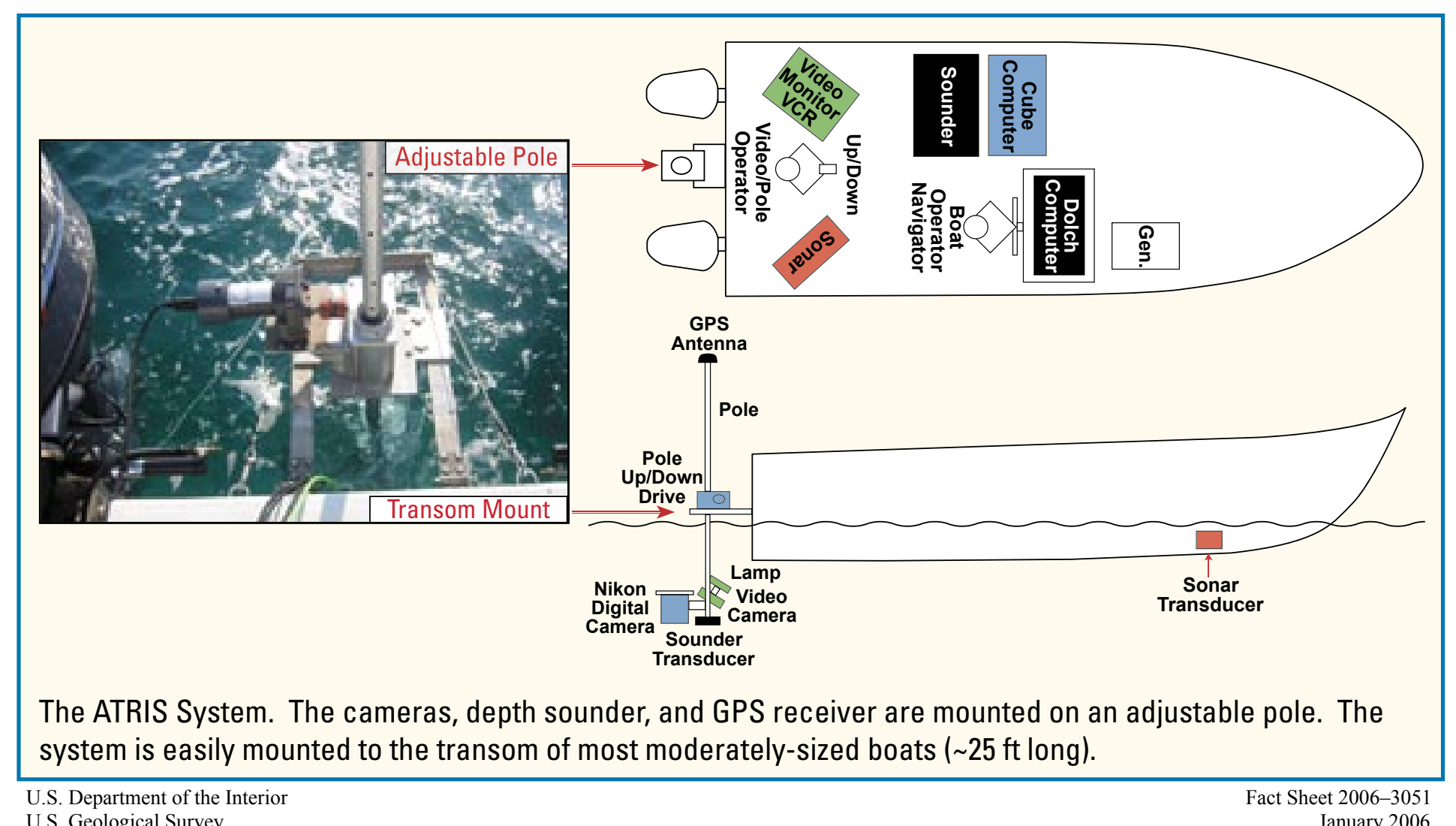

\section{Applications}

- Mapping

- Monitoring

- Habitat classification

- Change detection

- Impact assessment 
